\title{
Effect of Magnetic Field Treatments on Seed Germination of Melissa officinalis $\mathbf{L}$.
}

\section{Canan ÜLGEN ${ }^{*}$, Arzu BİRINCI YILDIRIM ${ }^{2}$, Arzu UÇAR TÜRKER ${ }^{1}$}

\author{
${ }^{1}$ Abant İzzet Baysal University, Faculty of Arts and Science, Department of Biology, Bolu, Turkey \\ ${ }^{2}$ Abant İzzet Baysal University, Faculty of Agriculture \& Natural Sciences, Department of Field Crops, Bolu, \\ Turkey
}

Received: 28 April 2017 - Revised: 26 July 2017 - Accepted: 03 August 2017

\begin{abstract}
Melissa officinalis L., commonly known as lemon balm, is a perennial herb belonging to Lamiaceae family. It has therapeutic properties, such as sedative, carminative, antispasmodic, anti-viral, wound healing, digestive, diuretic, diaphoretic, anti-septic and anti-thyroid. Lemon balm has been used for the treatment of headache, indigestion, colic, nervousness, cardiac problems, depression, rheumatism, indigestion, hypersensitivities, anxiety and depression traditionally. Beneficial effects of lemon balm are ascribed to the phenolic compounds such as rosmarinic acid, tannins and flavonoids. Studies showed that magnetic field applications in agriculture can be used to improve the quality and quantity of the product. Positive effects of the stationary magnetic field on the plant seed germination have been recorded with some plant species. In this study, effects of magnetic field on M. officinalis seeds were investigated. Seeds were sterilized in $0.1 \% \mathrm{HgCl}_{2}$ for 10 min and $70 \%$ Ethanol for 1-2 min. After surface sterilization of the seeds, they were placed in petri dishes containing Murashige and Skoog's medium with sucrose and agar. Neodymium block magnets (100 X 50 X 5 $\mathrm{mm})$ were used to create magnetic fields $(50 \mathrm{mT}$ and $100 \mathrm{mT})$. Ten seeds were placed in each petri plates and 10 petri plates were used for each treatment. Petri dishes containing surface sterilized seeds were placed in 3 different conditions [without magnetic field application (control) and magnetic field applications (low-50 mT and high-100 $\mathrm{mT}$ )] and the germination (radicle protrusion) was assessed. Seeds were exposed to magnetic fields for 1, 3, 6, 12, 24, 48, 72, 144 and 240 hours. The number of germinated seeds was recorded for 20 days. Best seed germination was obtained with $100 \mathrm{mT}$ magnetic field application for 1 hour $(52 \%)$. Seed germination rate was rather low (28 $\%)$ without magnetic field application (control). In consistent with $100 \mathrm{mT}$ magnetic field application, 1 hour exposure to $50 \mathrm{mT}$ magnetic field gave better germination rate $(36 \%)$ than control. The lowest seed germination was observed with 240 hours exposure to both magnetic fields ( $27 \%$ for $100 \mathrm{mT}$ and $16 \%$ for $50 \mathrm{mT})$. Magnetic field applications also decreased the seed germination time. Although seed germination was observed in 11. day with control, it was obtained in 7. day with both magnetic field applications. Magnetic field application enhanced the percentage of germinated seed and shortened the period of seed germination in M. officinalis.
\end{abstract}

Keywords: Magnetic field, Melissa officinalis, seed germination

\section{INTRODUCTION}

Melissa officinalis L. is a perennial bushy plant belonging to Lamiaceae family [1]. It is commonly called as 'lemon balm' because of its lemon-like flavor and fragrance [2]. Native to Europe, lemon balm is grown all over the world. It is grown not only in herb gardens or to attract bees, but also in crops for medicine, cosmetics, and furniture polish manufacturing [3].

*Corresponding Author E-mail: cananulgen@ibu.edu.tr 
It is an aromatic plant with useful applications in medicine, cookery and perfumery [4]. Lemon balm has been used traditionally for centuries as sedative, relaxant, stomachic, antispasmodic, carminative, diaphoretic, febrifuge, antiviral, antiseptic and nerve tonic in folk medicine. Traditional uses include healing wounds, relieving palpitations and relaxing the hearth, and treating toothache [5-10]. Preparations from leaves are used to treat feverish colds and headaches, to relieve menstrual cramps, and to calm nervous stomachs [11]. All of these actions of M. officinalis may be related to the high levels of phenolic acids especially rosmarinic acid [12]. Citral, citronellal and geraniol are the main components of essential oil of lemon balm in various climates [13].

In recent decades, physical techniques based on the application of magnetic fields are being developed in the agriculture sector [14]. Studies showed that low magnetic field applications in agriculture can be used to improve the quality and quantity of the product [15]. Numerous authors have reported the positive influence of the stationary magnetic field on the plant seeds. The treatment fastens plants development, improves germination and seedling growth, and activates protein formation and enzymes activity [16]. The investigations have shown that the treatment of the seeds with magnetic field increases the germination of nonstandard seeds and improves their quality [17]. Positive effects of the stationary magnetic field on the plant seed germination have been recorded with several plant species [14, 18-23]. The objective of this study was to investigate the effect of magnetic field on $M$. officinalis seed germination.

\section{MATERIAL and METHODS}

\subsection{Magnetic Field Establishment}

Neodymium block magnets $(100 \times 50 \times 5 \mathrm{~mm})$ were used to create a magnetic field. The magnets were fixed on the aluminum stand. Magnetic field ranging between $50 \pm 5 \mathrm{mT}$ and 100 $\pm 5 \mathrm{mT}$ was adjusted putting magnets side by side (magnet set) and magnetic canal was created between two magnet set. Magnetic field strength was measured using Teslameter. Petri dishes with a diameter of $90 \mathrm{~mm}$ were placed between magnet sets.

\subsection{Germination}

Seeds of M. officinalis were collected from Bolu, Turkey. Identification of the plant was made by using "Flora of Turkey and the East Aegean Islands" [1]. Seeds were washed with an anti-bacterial soap, rinsed with distilled water, surface sterilized by shaking for $15 \mathrm{~min}$ in 0.1 $\% \mathrm{HgCl}_{2}$, then washed with sterilized water three times and sterilized in $70 \%$ Ethanol for 1-2 min., and finally washed again with sterile water for three times. After surface sterilization of the seeds, seeds were placed in sterile, disposable petri dishes containing Murashige and Skoog's minimal organics (MSMO) medium [24] with $30 \mathrm{~g} / \mathrm{l}$ sucrose, $8 \mathrm{~g} / \mathrm{l}$ Difco Bacto-agar (pH 5.7, autoclaved for 20 minutes at $121^{\circ} \mathrm{C}$ and $105 \mathrm{kPa}$ ). Ten seeds were placed in each petri plates and 10 petri plates were used for each treatment. Petri dishes containing surface sterilized seeds were placed in 3 different conditions [without magnetic field application (control) and magnetic field applications (low-50 $\mathrm{mT}$ and high-100 mT)] and the germination (radicle protrusion) was assessed. Seeds were exposed to magnetic fields for 1, 3, 6, 12, 24, 48, 72, 144 and 240 hours. The number of germinated seeds was recorded for 20 days.

\section{RESULTS and DISCUSSION}

M. officinalis seeds were magnetically exposed to static magnetic field intensity of $50 \mathrm{mT}$ and $100 \mathrm{mT}$ for different time of exposure, 1, 3, 6, 12, 24, 48, 72, 144 and 240 hours, respectively. It was found that magnetic field intensity and exposure time were a very significant factor on the germination process of lemon balm seeds comparing with non-treated 
seeds (Figure 1, 2 and 3). Seeds were considered germinated when the protrusion of the radicle became evident. The highest seed germination was observed with $100 \mathrm{mT}$ magnetic field application for 1 hour (52\%) (Figure 3). Germination rate of control group (non-exposed seeds) was $28 \%$ that is nearly half of the treatment group with application of $100 \mathrm{mT}$ magnetic field for $1 \mathrm{hr}$. One hour exposure to $50 \mathrm{mT}$ magnetic field also gave better result than control (36\% and $28 \%$, respectively) (Figure 1, 2 and 3). Exposure time was a determinant factor for the germination of lemon balm seeds and best germination rate was obtained with low exposure time (1 hour). Increasing exposure time lowered germination rate in both magnetic field applications (100 $\mathrm{mT}$ and $50 \mathrm{mT}$ ) (Figure 1, 2 and 3) and the lowest seed germination was obtained with 240 hours in both of them ( $27 \%$ for $100 \mathrm{mT}$ and $16 \%$ for $50 \mathrm{mT}$ ). Furthermore, the onset of the germination occurred earlier with magnetically treated seeds. The length of time for seed germination was shortened with magnetic field applications observing seed germination in 7. day with both magnetic field applications and 11. day with non-treated seeds (Figure 2 and 3).

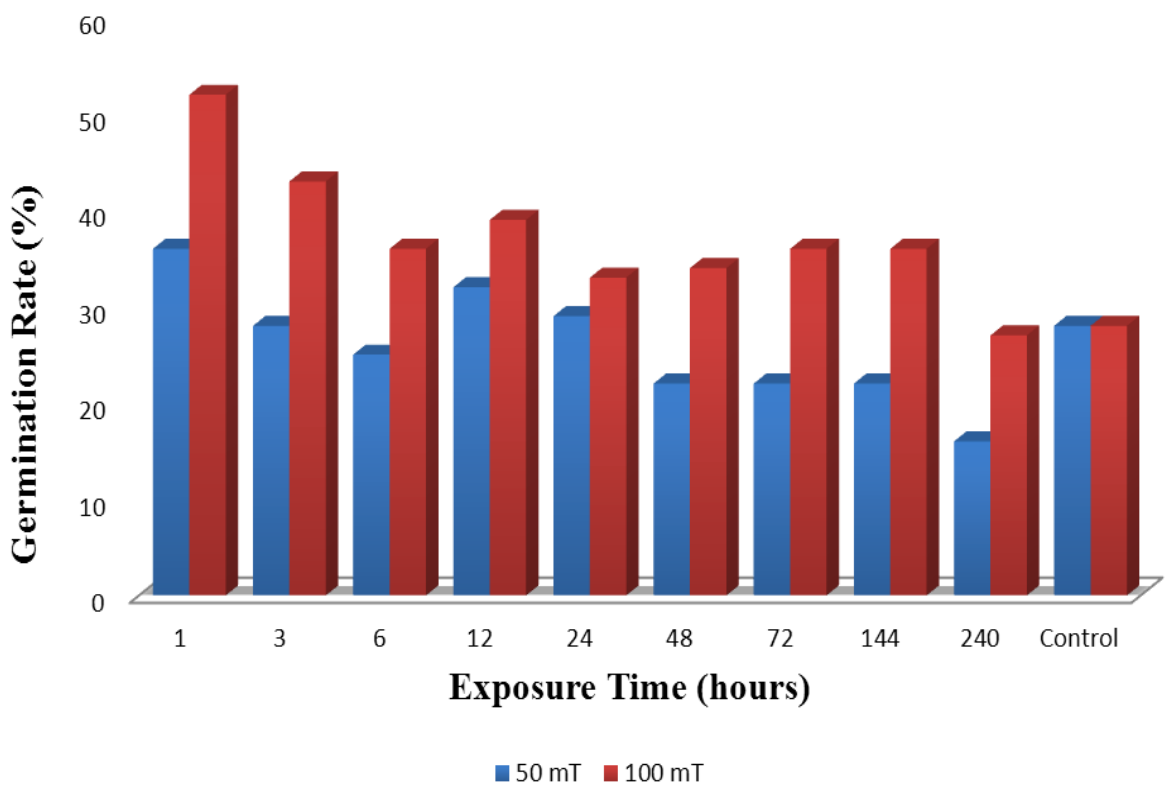

Figure 1. Effect of magnetic fields (50 mT and $100 \mathrm{MT})$ with different exposure times on germination rates of lemon balm seeds.

Yalçın and Tayyar [25] reported the effects of magnetic field on M. officinalis seeds. They were exposed the magnetic field strengths (1, 3, 9 and 15 times) in the range of 3.8-4.8 $\mathrm{mT}$ on the movable ground with the velocity of $1 \mathrm{~m} / \mathrm{sec}$. Germination rates were higher with magnetic field applications than control group. Many studies showed that $125 \mathrm{mT}$ and $250 \mathrm{mT}$ magnetic treatment produced a biostimulation on the initial growth stages and an increased the germination rate of several seeds such as rice, wheat and barley [18, 19, 21-23]. Magnetic field application enhanced the percentage of germinated seed on the treated group compared to nonexposed in both Salvia officinalis and Calendula officinalis [14]. Maize seeds exposed to magnetic field of $125 \mathrm{mT}$ or $250 \mathrm{mT}$ for varying periods of time germinated faster and the treated seedlings grew higher and heavier [23]. In wheat, Pittman and Ormrod [26] reported that the seedlings grown from magnetically treated seed $(180 \mathrm{mT})$ absorbed more moisture, respired more slowly, released less heat energy and grew faster than the untreated controls. In soybean, Kavi [27] observed that the seeds exposed to magnetic field of $300 \mathrm{mT}$ had increased capacity to absorb moisture. It was postulated that the ion-cyclotron resonance might interfere 
with the $\mathrm{Ca}^{2+}$ ion sequestering and thereby enable the increase in free $\mathrm{Ca}^{2+}$ concentration in the system. The increased $\mathrm{Ca}^{2+}$ concentration might signal the cell to enter into early mitotic cycle [28]. Garcia et al. [29] carried out an experiment on water absorption by lettuce seeds previously treated in a stationary magnetic field of 1 to $10 \mathrm{mT}$. They reported an increase in water uptake rate due to the applied magnetic field, which might be the explanation for the increase in the germination of treated lettuce seeds. They concluded that changes in intracellular levels of $\mathrm{Ca}^{2+}$ and in other ionic current density across cellular membrane caused alteration in osmotic pressure and changed in the capacity of cellular tissues to absorb water. Reina and Pascual [20] investigated the influence of a stationary magnetic field on water relations in lettuce seeds and observed an increase in water uptake rate due to the applied magnetic field. They deduced that magnetic field interacting with ionic current in the cell membrane changed the ionic conductivity of the membrane and therefore, the concentration and the osmotic pressure in both sides of the membrane, and this change in the osmotic pressure altered the mechanism of water imbibition of seeds [20].

\section{$50 \mathrm{mT}$}

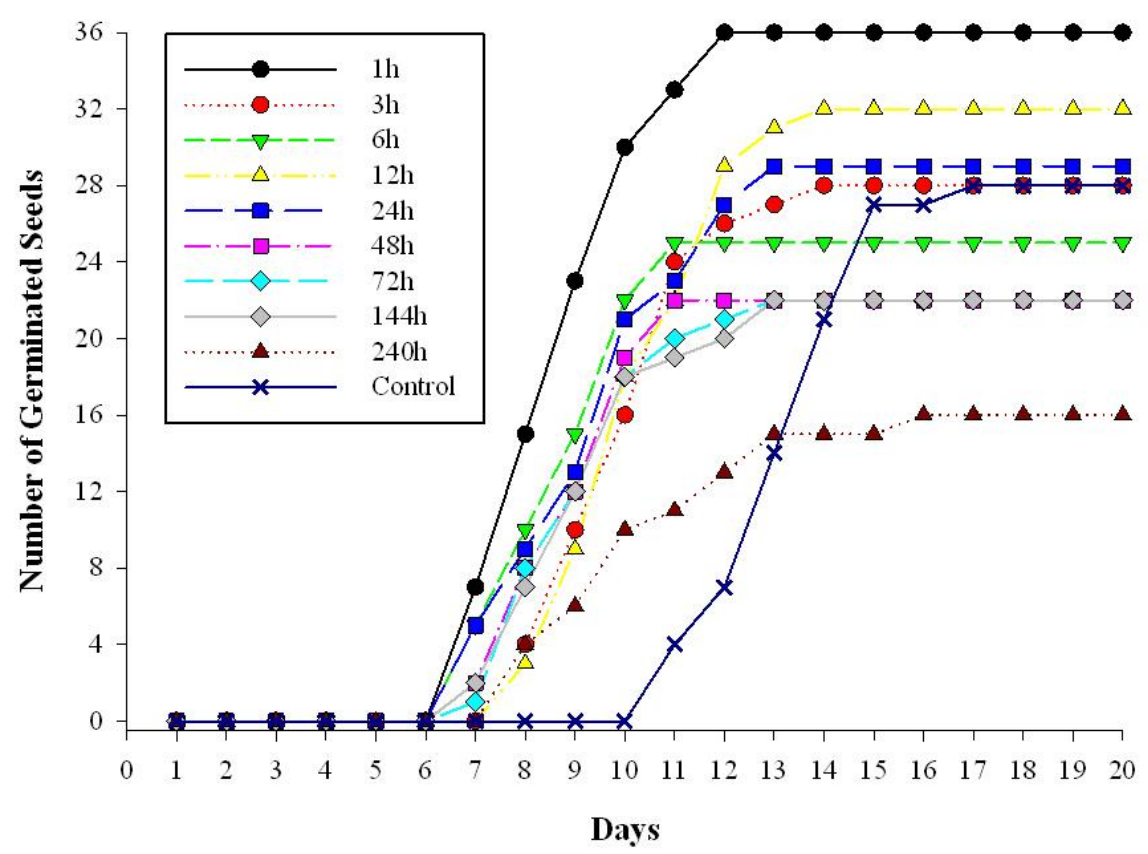

Figure 2. Effect of $50 \mathrm{mT}$ magnetic field on germination of lemon balm seeds.

In recent decades, physical techniques based on the application of magnetic fields are being developed in the agriculture sector [14]. Studies showed that low magnetic field applications in agriculture can be used to improve the quality and quantity of the product [15]. Numerous authors have established the positive influence of the stationary magnetic field on the plant seeds. The treatment fastens plants development, improves germination and seedling growth, and activates protein formation and enzymes activity [16]. The investigations have shown that the treatment of the seeds with magnetic field increases the germination of nonstandard seeds and improves their quality [17].

In consistent with other studies, our results showed that germination percentages were higher for magnetically treated lemon balm seeds. Also, germination time was significantly reduced when seeds were exposed to magnetic fields. Our results suggest that magnetic treatments can be used as a physical technique to improve the germination of $M$. officinalis seeds. 


\section{$100 \mathrm{mT}$}

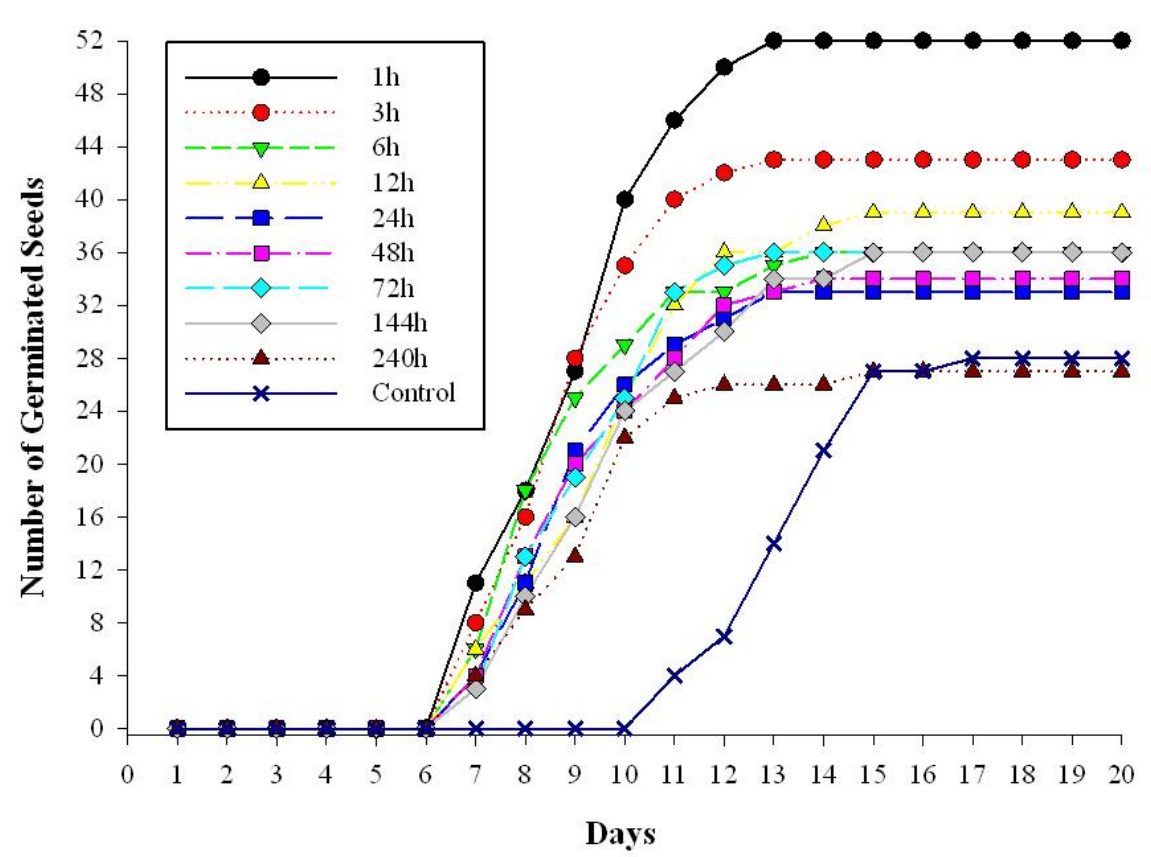

Figure 3. Effect of $100 \mathrm{mT}$ magnetic field on germination of lemon balm seeds.

\section{Acknowledgement}

This study is the part of a Ph.D. thesis of Canan Ülgen and financially supported by Abant Izzet Baysal University, Scientific Research Projects (BAP 2016.03.01.1027).

\section{Conflict of Interests}

Authors declare that there is no conflict of interests.

\section{REFERENCES}

[1]. Davis P.H. (1982). Flora of Turkey and the East Aegean Islands vol. 7. Edinburgh: Edinburgh University Press.

[2]. Moradkhani, H., Sargsyan, E., Bibak, H., Naseri, B., Sadat-Hosseini, M., Fayazi-Barjin, A., \& Meftahizade, H. (2010). Melissa officinalis L., a valuable medicine plant: A review. Journal of Medicinal Plants Research, 4(25), 2753-2759.

[3]. Meftahizade, H., Lotfi, M., \& Moradkhani, H. (2010). Optimization of micropropagation and establishment of cell suspension culture in Melissa officinalis L. African Journal of Biotechnology, 9(28), 4314-4321.

[4]. Tavares, A. C., Pimenta, M. C., \& Goncalves, M. T. (1996). Micropropagation of Melissa officinalis L. through proliferation of axillary shoots. Plant cell reports, 15(6), 441-444.

[5]. Grieve, M. (1982). A Modern Herbal, Vol 1. New York: Dover Publications.

[6]. Chevallier, A. (1996). The encyclopedia of medicinal plants. London: Dorling Kindersley; (p. 185). ISBN 9-780751-303148.

[7]. Baytop, T. (1999). Türkiye' de Bitkiler ile Tedavi. Istanbul: Nobel Tip Kitabevleri.

[8]. Petersen, M., \& Simmonds, M. S. (2003). Rosmarinic acid. Phytochemistry, 62(2), 121125. 
[9]. Weitzel, C., \& Petersen, M. (2011). Cloning and characterisation of rosmarinic acid synthase from Melissa officinalis L. Phytochemistry, 72(7), 572-578.

[10]. Abdellatif, F., Boudjella, H., Zitouni, A., \& Hassani, A. (2014). Chemical composition and antimicrobial activity of the essential oil from leaves of Algerian Melissa officinalis L. EXCLI journal, 13, 772.

[11]. Dobelis, I. N. (1986). Magic and medicine of plants. Pleasantville, NY: Reader's Digest Association, p702.

[12]. Barros, L., Dueñas, M., Dias, M. I., Sousa, M. J., Santos-Buelga, C., \& Ferreira, I. C. (2013). Phenolic profiles of cultivated, in vitro cultured and commercial samples of Melissa officinalis L. infusions. Food chemistry, 136(1), 1-8.

[13]. Moradkhani, H., Sargsyan, E., Bibak, H., Naseri, B., Sadat-Hosseini, M., Fayazi-Barjin, A., \& Meftahizade, H. (2010). Melissa officinalis L., a valuable medicine plant: A review. Journal of Medicinal Plants Research, 4(25), 2753-2759.

[14]. Flórez, M., Martínez, E., \& Carbonell, M. V. (2012). Effect of magnetic field treatment on germination of medicinal plants Salvia officinalis L. and Calendula officinalis L. Polish Journal of Environmental Studies, 21(1).

[15]. Racuciu, M., Galugaru, G., \& Creanga, D. E. (2006). Static magnetic field influence on some plant growth. Romanian Journal of Physics, 51(1/2), 245.

[16]. Aladjadjiyan, A. (2010). Influence of stationary magnetic field on lentil seeds. Int. Agrophys, 24(3), 321-324.

[17]. Subber, A. R., Hail, R. C. A., Jabail, W. A., \& Hussein, H. F. (2012). Effects of magnetic field on the growth development of Zea mays seeds. J. Nat. Prod. Plant Resour, 2(3), 456-459.

[18]. Carbonell, M. V., Martinez, E., \& Amaya, J. M. (2000). Stimulation of germination in rice (Oryza sativa L.) by a static magnetic field. Electro-and magnetobiology, 19(1), 121128.

[19]. Martinez, E., Carbonell, M. V., \& Amaya, J. M. (2000). Stimulation on the initial stages on growth of barley (Hordeum vulgare, L.) by $125 \mathrm{mT}$ stationary magnetic field. $J$. Electro. Magnetic Biol, 19(3), 271-277.

[20]. Garcia Reina, F., \& Arza Pascual, L. (2001). Influence of a stationary magnetic field on water relations in lettuce seeds. Part I: Theoretical considerations. Bioelectromagnetics, 22(8), 596-602.

[21]. Martinez, E., Carbonell, M. V., \& Florez, M. (2002). Magnetic biostimulation of initial growth stages of wheat (Triticum aestivum, L.). Electromagnetic Biology and Medicine, 21(1), 43-53.

[22]. Flórez, M., Carbonell, M. V., \& Martínez, E. (2004). Early sprouting and first stages of growth of rice seeds exposed to a magnetic field. Electromagnetic Biology and Medicine, 23(2), 157-166.

[23]. Florez, M., Carbonell, M. V., \& Martínez, E. (2007). Exposure of maize seeds to stationary magnetic fields: Effects on germination and early growth. Environmental and experimental botany, 59(1), 68-75.

[24]. Murashige, T., \& Skoog, F. (1962). A revised medium for rapid growth and bio assays with tobacco tissue cultures. Physiologia plantarum, 15(3), 473-497.

[25]. Yalçin, S., \& Tayyar, Ş. (2011). Oğulotu tohumlarının çimlenmesi ve fide gelişimi üzerine manyetik alanın etkisi. Yüzüncü Yıl Üniversitesi Tarım Bilimleri Dergisi, 21(3), 190-197. 
[26]. Pittman, U. J., \& Ormrod, D. P. (1970). Physiological and chemical features of magnetically treated winter wheat seeds and resultant seedlings. Canadian journal of plant science, 50(3), 211-217.

[27]. Kavi, P. S. (1977). The effect of magnetic treatment of soybean seed on its moisture absorbing capacity [India]. Science and Culture, 43(9): 405-406.

[28]. Vashisth, A., Singh, R., \& Joshi, D. K. (2013). Effect of Static Magnetic Field on Germination and Seedling Attributes in Tomato (Solanum lycopersicum). Journal of Agricultural Physics, 13(2), 182-185.

[29]. Reina, F. G., Pascual, L. A., \& Fundora, I. A. (2001). Influence of a stationary magnetic field on water relations in lettuce seeds. Part II: experimental results. Bioelectromagnetics, 22(8), 596-602. 